\title{
Reinforcement effect of fiber and deoiled asphalt on high viscosity rubber/SBS modified asphalt mortar
}

\author{
Wu Mengmeng, Li Rui, Zhang Yuzhen*, Wei Jianming, Lv Yuchao and \\ Ding Xuemei
}

State Key Laboratory of Heavy Oil Processing, China University of Petroleum (East China), Qingdao, Shandong 266555, China

(C) China University of Petroleum (Beijing) and Springer-Verlag Berlin Heidelberg 2014

\begin{abstract}
In this paper we investigate the reinforcement mechanism of high viscosity rubber/SBS modified asphalt mortar mixed with fiber (mineral, lignin or carbon fiber) and deoiled asphalt (DOA). The softening point, penetration and viscosity tests were conducted to characterize the engineering properties of asphalt-fiber mortar. The microstructure of fiber was observed using scanning electron microscopy (SEM), and the results indicated that fiber can effectively improve the toughness of asphalt matrix through forming a spatial network structure, and then adhesion and stabilization of asphalt binder. The cone penetration test was designed to study the rheological property of fiber modified asphalt. The results indicated that the reinforcement effect increased with fibers and DOA fraction increasing to a certain threshold, and the optimal fiber content was dependent on the fiber type and its length. Fiber content and filler-asphalt ratio had significant effects on the softening point, penetration, viscosity and cone penetration of asphalt mortar.
\end{abstract}

Key words: Asphalt mortar, fiber, filler-asphalt ratio, reinforcement, mechanical property

\section{Introduction}

Asphalt mortar is a black and highly viscous mixture of asphalt and fillers, with which, together with added coarse rock aggregate, many roads have been built all round the world. The original asphalt from petroleum refining residue is altered by addition of rubber and polymers (like styrenebutadiene-styrene block copolymer (SBS)), giving polymer modified bitumen. Addition of filler, in this case, very fine limestone powder, about 1:1 with the polymer-modified bitumen can improve the properties of the "bitumen" or "asphalt" binding the coarse aggregate in the road material. Moisture beneath pavement softens subgrade soil and weakens base materials to destroy the structural capacity of the pavement (Castro and Sanchez, 2008; Gorkem and Sengoz, 2009; Airey et al, 2008). On the other hand, traffic load induces daily damages such as fatigue cracks and pavement failures (Chen and Huang, 2008). Therefore, scientists and engineers are constantly trying to improve the performance of asphalt mixtures and pavements (Ramsamooj, 2001), and have found that modification of the asphalt binder is a good choice (Rahnama, 2009). Among various modifiers for asphalt, fibers have received much attention due to their

*Corresponding author. e-mail: zhangyuzhen1959@163.com

Received December 3, 2013 good improvement effects (Yildirim, 2007; Wu et al, 2008). Adding fibers to asphalt can enhance material strength, anti-fatigue properties and ductility due to their inherent compatibility (Huang and White, 1996). Fibers provide a high surface area which is favorable to the adsorption of asphalt, as a result, they can stabilize asphalt to prevent it leaking during pavement use (Echols, 1989; Tapkin, 2008), and fibers are widely used in stone matrix asphalt and open-graded friction course (Hassan et al, 2005; Peltonen, 1991).

DOA is a by product from heavy oil, and it is deoiled deeply to get rid of saturates and aromatics as much as possible. DOA is a hard, crisp solid or powder at room temperature, with similar black or brown appearance to coal. As a by-product of heavy oil refining process, DOA is usually used as coking materials, binding materials and blast furnace fuel (Zhang et al, 2010). Converting DOA to products with high added value will be an economically competitive route. Because of its high carbon content $(>80 \mathrm{wt} \%)$, very low ash content, cheapness and abundant source, DOA was used as modifiers for asphalt mortar in this work, for comparison purpose with fiber modified asphalt mortar. However, fibers and DOA may increase asphalt mortar stiffness, subsequently increase the brittleness of the asphalt mixture, leading to pavement distress such as disintegration and fracture under the influence of climate and traffic loading. Thus, it is an important issue to determine the optimal fiber and DOA 
contents that can improve asphalt properties to a satisfactory level at a minimum cost. The objectives of this study are 1) to characterize the behavior of asphalt-fiber mortar, 2) to evaluate the effect of fibers and DOA on asphalt mortar, and 3) to decide the optimum content of fibers and DOA in asphalt mortar.

\section{Experimental}

\subsection{Experimental materials}

\subsubsection{Asphalt}

The high viscosity rubber/SBS-modified asphalt used in this work was provided by the PetroChina Fuel Oil Company Limited, and the physical properties of the rubber/SBS modified asphalt are presented in Table 1.

Table 1 Physical properties of asphalt binder

\begin{tabular}{ccc}
\hline Test items & Measured value & Specification \\
\hline Penetration at $25^{\circ} \mathrm{C}$ & $6.3 \mathrm{~mm}$ & JTG E20-2011/T0604 \\
Ductility at $5{ }^{\circ} \mathrm{C}$ & $37 \mathrm{~cm}$ & JTG E20-2011/T0605 \\
Ductility at $10^{\circ} \mathrm{C}$ & $58 \mathrm{~cm}$ & JTG E20-2011/T0605 \\
Softening point & $84.1^{\circ} \mathrm{C}$ & JTG E20-2011/T0606 \\
\hline
\end{tabular}

Notes: JTG E20-2011: The Traffic Industry Standard (China) "Standard Test Methods of Bitumen and Bituminous Mixtures for Highway Engineering".

T0604: Penetration Test for Bituminous Materials in JTG E20-2011. T0605: Test Method for Ductility of Bituminous Materials in JTG E202011.

T0606: Test Method for Softening Point of Bitumen (ring and ball method) in JTG E20-2011.

\subsubsection{Fibers and DOA}

Three typical fiber types were investigated. The mineral fiber and lignin fiber were produced by the Jiangsu TianLong Continuous Basalt Fiber Hi-Tech Co. Ltd., and the carbon fiber was produced by the Beijing Pan China Municipal Tec. CO. The physical properties of the three types of fiber used are presented in Table 2 (provided by the manufacturer). DOA is a solid hydrocarbon product, and its softening point is 96 ${ }^{\circ} \mathrm{C}$.

Table 2 Main characteristics of the fibers

\begin{tabular}{ccccc}
\hline Fibers & $\begin{array}{c}\text { Carbon } \\
\text { fiber }\end{array}$ & $\begin{array}{c}\text { Mineral } \\
\text { fiber }\end{array}$ & $\begin{array}{c}\text { Lignin } \\
\text { fiber }\end{array}$ & Specification \\
\hline Diameter, $\mu \mathrm{m}$ & $12-14$ & $13-16$ & $12-15$ & ASTM D2130 \\
$\begin{array}{c}\text { Length, mm } \\
\text { Tensile strength, } \\
\mathrm{MPa}\end{array}$ & $0.5-1.0$ & 6.0 & $0.5-2.0$ & ASTM D204 \\
$\begin{array}{c}\text { Density, g/cm } \\
\text { Melting point, }{ }^{\circ} \mathrm{C}\end{array}$ & $1.3-2.0$ & $2.65-3.05$ & $/$ & ASTM D3800 \\
$\begin{array}{c}\text { Elongation at break, } \\
\%\end{array}$ & $/$ & 1600 & $<250$ & ASTM D276 \\
\hline
\end{tabular}

\subsubsection{Mineral powder}

The limestone powder was screened using a 0.075 $\mathrm{mm}$ sieve to eliminate coarse particles. The basic physical properties of the limestone powder are presented in Table 3.

Table 3 Physical properties of limestone powder

\begin{tabular}{ccccc}
\hline $\begin{array}{c}\text { Plasticity } \\
\text { index }\end{array}$ & $\begin{array}{c}\text { Density } \\
\mathrm{g} / \mathrm{cm}^{3}\end{array}$ & $\begin{array}{c}\text { Hydrophilic } \\
\text { coefficient }\end{array}$ & $\begin{array}{c}\text { Water absorption } \\
\%\end{array}$ & Soundness \\
\hline 3.1 & 2.7 & 0.8 & 0.3 & Qualified \\
\hline
\end{tabular}

\subsection{Experimental methods}

\subsubsection{Preparation of fiber-asphalt mortar}

Filler (limestone powder) and fibers were separately put into a $105^{\circ} \mathrm{C}$ oven for $24 \mathrm{~h}$ to ensure moisture-free surfaces of the filler and fiber. The solid asphalt $(600 \mathrm{~g})$ stored in a sealed can was preheated at $160{ }^{\circ} \mathrm{C}$ for $2 \mathrm{~h}$ to make it liquid for mixing. In order to investigate the effects of fibers on asphalt mortar, different fiber contents (by weight) in the asphalt mortar were studied. The fiber content of $0 \mathrm{wt} \%$ represented pure asphalt mortar. The fiber and filler were weighed and slowly added to the asphalt under stirring at $500 \mathrm{rpm}$ to prevent the fiber from possibly agglomerating. Then they were mixed at $160{ }^{\circ} \mathrm{C}$ for approximately $30 \mathrm{~min}$ under stirring to produce homogeneous fiber modified asphalt mortar.

\subsubsection{Softening point}

The softening point of asphalt mortar was obtained with WSY-025D asphalt softening point tester with a steel ball of $3.5 \mathrm{~g}$ and steel ring of $20 \mathrm{~mm}$ in diameter (Wuxi Petroleum Asphalt Equipment Co. Ltd., China). The sample was cooled in a water bath of $5{ }^{\circ} \mathrm{C}$ for $15 \mathrm{~min}$. Then, it was heated at a heating rate of $5^{\circ} \mathrm{C} / \mathrm{min}$, and the softening point was taken at the temperature at which the mortar sample became soft enough to allow the ball to fall a distance of $25.4 \mathrm{~mm}$. The softening point is also known as the ring and ball softening temperature $\left(T_{R \& B}\right)$.

\subsubsection{Penetration test}

The penetration of asphalt mortar was obtained with a WSY-026 penetration tester (Wuxi Petroleum Asphalt Equipment Co. Ltd., China). The penetration experiment was conducted to measure the hardness and viscosity of asphalt mortar. Penetration is expressed in units of $0.1 \mathrm{~mm}$, which is the depth of penetration of a standard needle under a 100 $\mathrm{g}$ load after a $5 \mathrm{~s}$ loading time at a specified temperature. The asphalt mortar sample was put in air for 1 hour, then it was put in a water bath of $25^{\circ} \mathrm{C}$ for 1 hour to equilibrate thermally before the penetration test.

\subsubsection{Cone penetration test}

The cone penetration of asphalt mortar was obtained with a WSY-026 penetration tester (Wuxi Petroleum Asphalt Equipment Co. Ltd., China). The cone penetration experiment was conducted to measure asphalt-fiber mortar's resistance to flow and shear. Cone penetration is expressed in units of 0.1 $\mathrm{mm}$, which is the penetration depth of a standard cone under a $200 \mathrm{~g}$ load into the asphalt mortar sample. The prepared sample was kept at the room temperature for $40 \mathrm{~min}$ until it cooled and solidified, and then put in a water bath at $25^{\circ} \mathrm{C}$ for 
more than $1 \mathrm{~h}$. After that, the sample was taken out from the water bath and an iron cone was put on the sample surface. The cone would gradually penetrate into the asphalt mortar until it was stable without further sinking, then the sink depth was measured and recorded. It should be noted that the cone would not completely penetrate into the sample mixture.

\subsubsection{Viscosity}

Viscosity tests were carried out using a standard rotational (or Brookfield) viscometer (Model DV-II+, Brookfield Engineering Inc., USA). During the test, as the spindle turned, the fluid resistance to rotation was recorded by a calibrated spring connected to a dial where the data were reported. Viscosity (as measured with the rotational viscometer) is not an absolute property of bituminous binders, however, it may exhibit non-Newtonian behavior. Hence, viscosity can be used for comparative purposes when temperature, shear rate and torque are similar, as in the case of the present study.

\subsubsection{Rheological measurement}

The low temperature creep test was carried out to determine the low temperature performance of the asphalt mortar using the bending beam rheometer (TEBBR, Cannon Instrument Company, Japan). In this test, the BBR sample beams $(125 \mathrm{~mm} \times 12.5 \mathrm{~mm} \times 6.25 \mathrm{~mm})$ were cooled in a methanol bath for $60 \mathrm{~min}$ at a constant temperature of -6 ${ }^{\circ} \mathrm{C},-12{ }^{\circ} \mathrm{C}$ and $-18{ }^{\circ} \mathrm{C}$, respectively. Then, the sample beam was placed on two stainless steel supports and loaded with $100 \mathrm{~g}$. The deflection was monitored with time and used for calculation of the stiffness as a function of time. The creep stiffness $(S)$ and creep rate $(m)$ of the binders were determined at loading time of $60 \mathrm{~s}$. The two parameters (creep stiffness and creep rate) were used as the low-temperature characteristics of the asphalt mortars.

\section{Results and discussion}

\subsection{Microstructures of fiber and DOA}

To understand fiber's reinforcement mechanism, the microstructures of different fibers were observed by scanning electron microscopy (SEM) and presented in Fig. 1. The difference of fiber microstructures would result in different asphalt adsorption. As shown in Fig. 1, mineral fiber had a smooth surface texture and showed poor asphalt adsorption. However, the lignin fiber had a rough surface texture, which is favorable to the adhesion of asphalt; hence it can absorb more asphalt and stabilize them. DOA was porous and had relatively rough cross section. Carbon fiber, like mineral fiber, was also round, not like the lignin fiber. Fibers can form a three dimensional network in asphalt, and this network can be retained at high temperature. This network of fibers could be favorable to the formation of a thick coating of mastic without draining down (Putman and Amirkhanian, 2004). It could also resist crack propagation and aggregate sliding at the interface, allocate stress, and reduce stress concentration, thereby improving the integral strength of the asphalt binder (Chen et al, 2004; Maurer and Malasheskie, 1989).

\subsection{Softening point and penetration}

The softening point $T_{R \& B}$ is another important performance
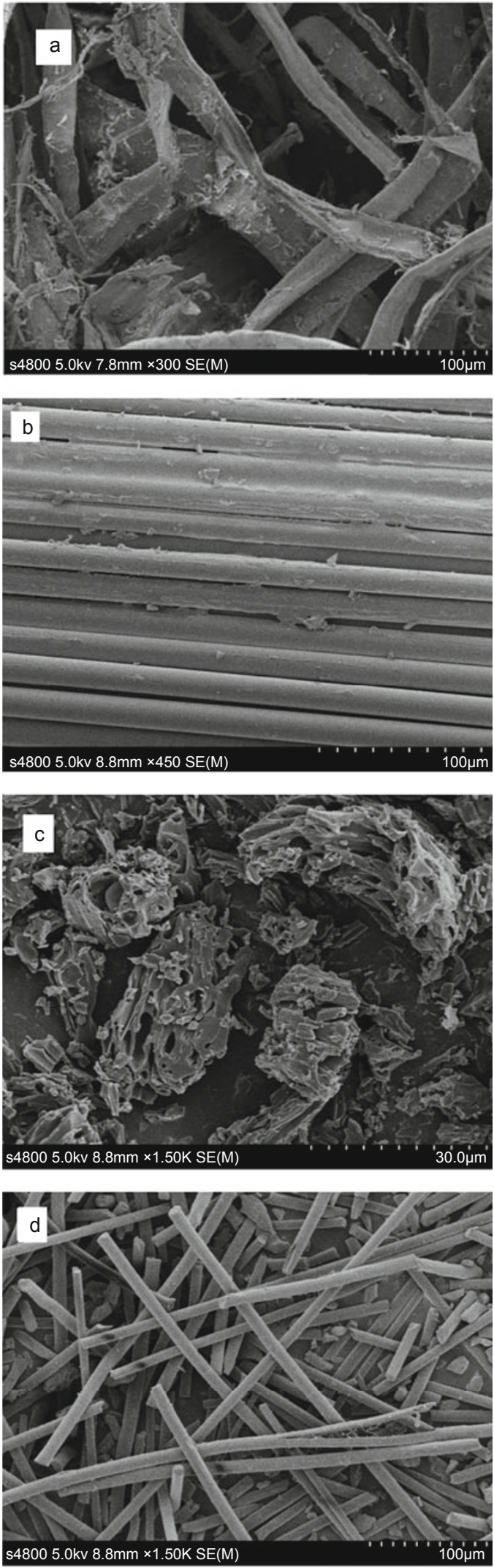

Fig. 1 SEM images of fibers and DOA: a) Lignin fiber; b) Mineral fiber; c) DOA; d) Carbon fiber

criterion for asphalt mortars. The $T_{R \& B}$ increased rapidly with the addition of fibers and an increase of filler to asphalt ratio as shown in Fig. 2. It can be seen that, with the same filler to asphalt ratio, the $T_{R \& B}$ of the carbon fiber modified asphalt 

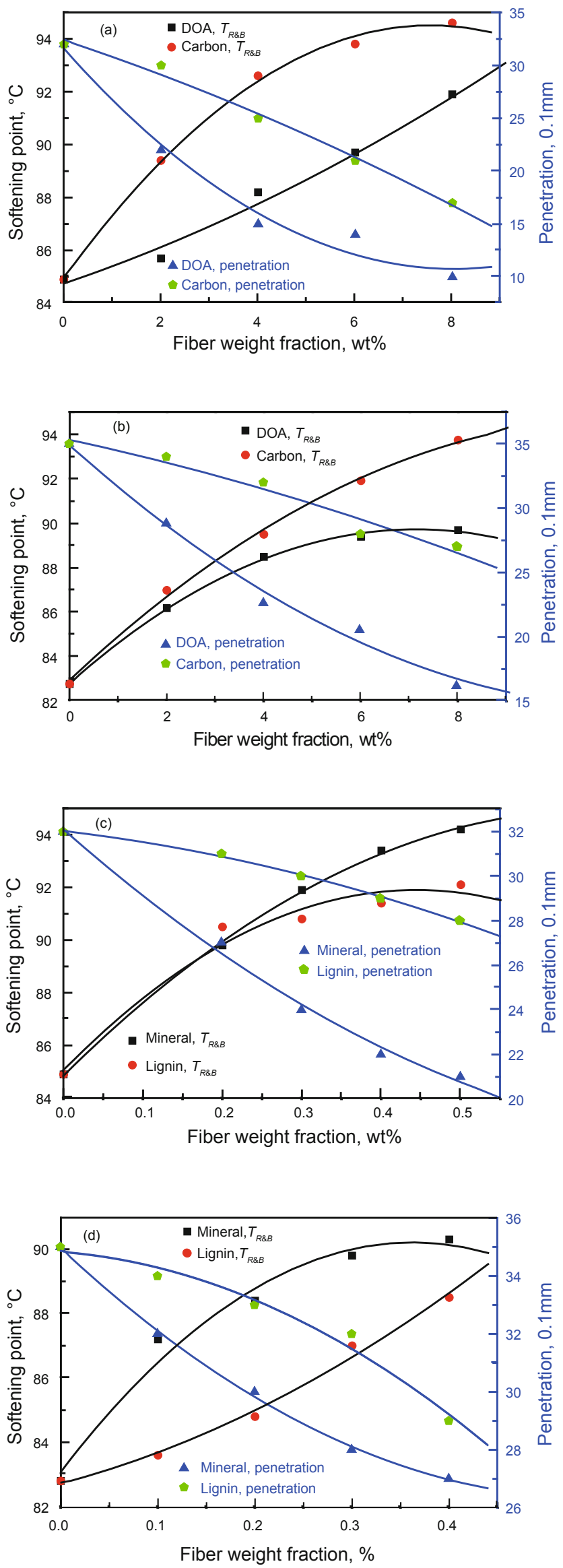

Fig. 2 Softening point and penetration of fiber modified asphalt mortars with a filler-asphalt ratio of $1.0(\mathrm{a}, \mathrm{c})$ and $0.8(\mathrm{~b}, \mathrm{~d})$ by weight mortar was higher than that of DOA modified asphalt mortar, and the $T_{R \& B}$ of mineral fiber modified asphalt mortar was higher than that of the lignin modified asphalt mortar. As the maximum temperature of the pavements is approximately $60{ }^{\circ} \mathrm{C}$ in summer, addition of fibers can resolve the effect of high temperature on pavements (Chen and Lin, 2005). In the penetration test, similar results were obtained to $T_{R \& B}$, as shown in Fig. 2. Note that lignin and carbon fibers have the same fiber length, but resulted in completely different $T_{R \& B}$ and penetrations. The reason is that carbon fibers cannot become entangled with each other (Fitzgerald, 2000; Bruce, 2003).

\subsection{Viscosity}

The viscosity of carbon fiber modified asphalt mortar is shown in Fig. 3. It can be seen that the viscosity decreased with increasing temperature, but it increased with the increase of filler-asphalt ratio, indicating that the fiber's absorption of asphalt resulted in an increased viscosity of asphalt and improved interface adhesion between asphalt and fiber or aggregate. This increase in viscosity primarily results from fiber reinforcement, and the high viscosity could lead to reduced draindown of asphalt mortar and reduced pavement rut formation. In other words, the addition of fibers into an asphalt mixture can enhance the pavement resistance to rutting at high temperature (Tapkin, 2008). There was a slight increase in asphalt viscosity at a fiber content of 2 wt $\%$ because fiber acted only as a dispersing material. At the fiber content of $4 \mathrm{wt} \%$, the viscosity greatly increased since the fiber began to form a localized network structure. The network resulted in an increase in viscosity with the increase of fiber content. When the fiber content was $6 \mathrm{wt} \%$,
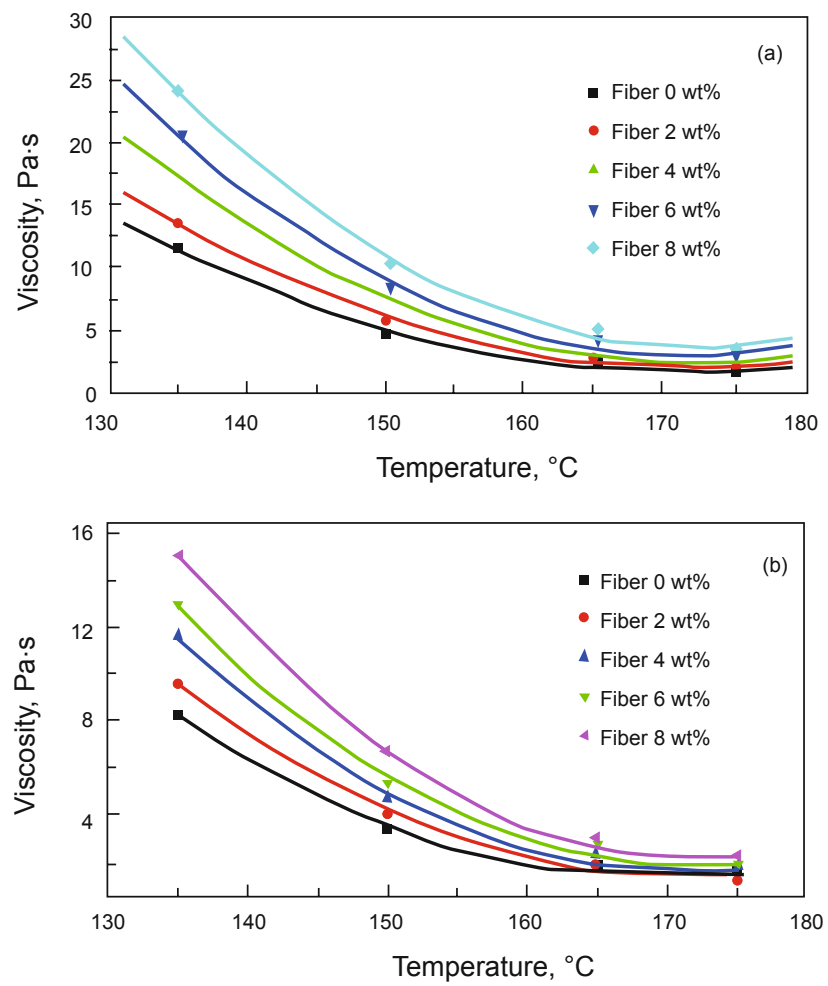

Fig. 3 Viscosity of carbon fiber modified asphalt mortar with a filler-asphalt ratio of 1.0 (a) and 0.8 (b) by weight 
the local networks gradually interacted to each other to form a continuous network throughout the asphalt. This network acted as a support structure, reinforcing the asphalt and resisting deformation (Tapkin et al, 2010).

The viscosity of different fiber modified asphalt mortars is shown in Fig. 4. The mineral fiber or lignin at $0.3 \mathrm{wt} \%$ concentration showed a significant increase in viscosity. Thus, for mineral fiber or lignin, a concentration of $0.3 \mathrm{wt} \%$ was found to be optimum. According to this reinforcement criterion, the optimum content of DOA or carbon fibers was determined to be $4 \mathrm{wt} \%$. Mixing more fibers than the optimum concentration is not economical; in addition, it could make asphalt mortar brittle, resulting in the pavement deteriorating. What should be noted is that the optimum content of fibers is one of factors for the reinforcement effect of asphalt mortar. Other factors including cost, fiber-fiber interaction and the structure of fibers need to be taken into account. Since short fibers can give less increase in viscosity than long ones, long fibers should be used to achieve the expected viscosity improvement. However, long fibers may cause mixing problems (Fu et al, 2000).
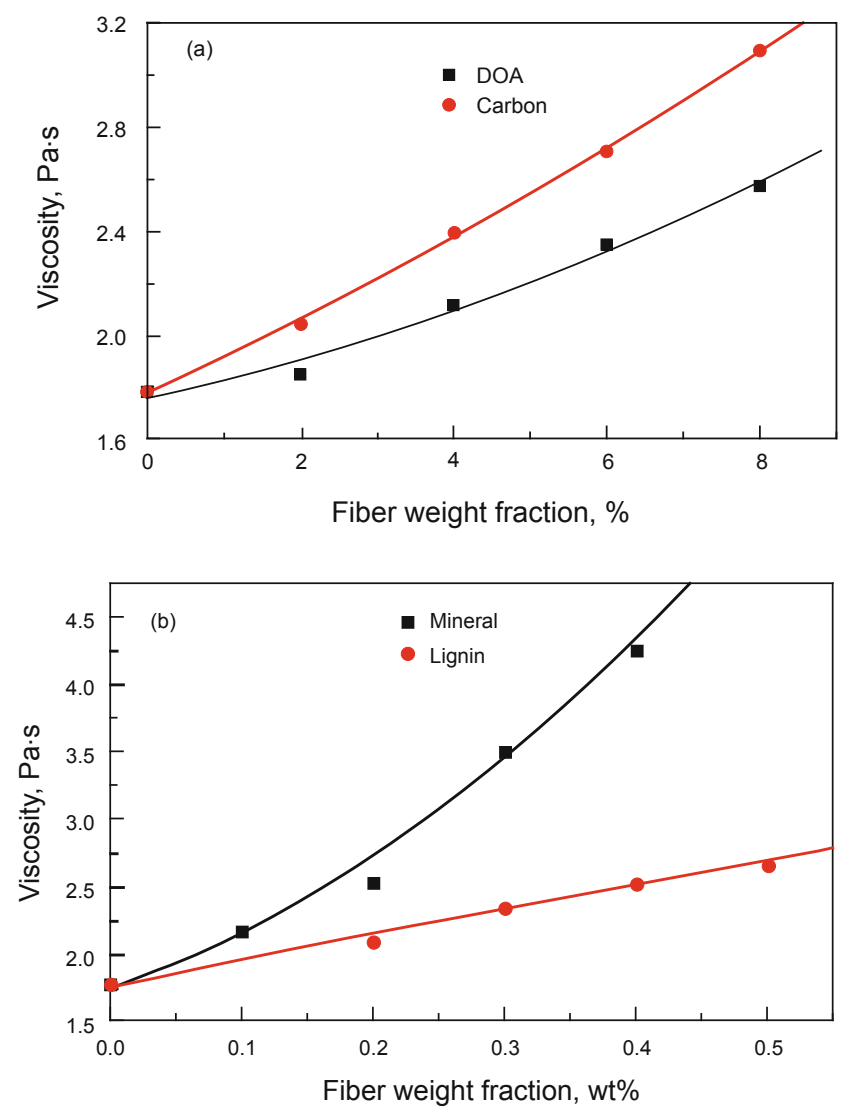

Fig. 4 Viscosity of asphalt mixed with different fibers at $165^{\circ} \mathrm{C}$, with filler-asphalt ratio of 0.8 by weight

\subsection{Cone penetration test}

The measured cone penetration (cone sink depth) and calculated shear stress are presented in Table 4. It can be seen that with the lignin fiber content increase, the cone sink depth reduced while the shear stress increased. The cone penetration of fiber modified asphalt mortar decreased in the order (or increased in the order for shear stress) as follows: lignin fiber, mineral fiber and DOA, and the cone penetration of the carbon fiber modified asphalt mortar was consistent with that of lignin modified asphalt mortar. DOA has the greatest effect on reducing the cone penetration and improving the shear stress, which may be due to composition, that is to say, higher content of resin and asphaltene. The mineral fiber modified asphalt mortar had a higher shear stress than the lignin fiber modified asphalt mortar, and the reason may be that long fibers can increase the viscosity of asphalt mortar more significantly than short ones (Fu et al, 2000).

Table 4 Cone penetration and shear stress of fiber modified asphalt mortar with filler-asphalt ratio of 0.8 by weight

\begin{tabular}{cccc}
\hline Fibers & $\begin{array}{c}\text { Fiber fraction } \\
\text { wt } \%\end{array}$ & $\begin{array}{c}\text { Cone sink depth } \\
\text { mm }\end{array}$ & $\begin{array}{c}\text { Shear stress } \\
\mathrm{MPa}\end{array}$ \\
\hline DOA & 4.0 & 20 & 105 \\
Carbon fiber & 4.0 & 29 & 50 \\
Mineral fiber & 0.3 & 24 & 73 \\
\hline & 0.1 & 32 & 41 \\
Lignin fiber & 0.2 & 30 & 47 \\
& 0.3 & 29 & 50 \\
& 0.4 & 28 & 54 \\
\hline
\end{tabular}

The reasons for these experimental results are explained as follows: the three-dimensional spatial network structure of the fiber improved the performance of the asphalt mortar. In addition, the fiber has high tensile strength which can hold asphalt and resist flowing and crack propagation more effectively (Xu et al, 2010; Li, 1992). Moreover, fiber can absorb the light components in asphalt and increase the viscosity of asphalt, therefore, fiber increases the shear strength of asphalt.

\subsection{Viscoelastic behavior}

The low-temperature creep stiffness $(S)$ and creep rate $(m)$ for lignin modified asphalt mortars were determined using the bending beam rheometer (BBR) at three different temperatures, and the results are shown in Figs. 5 and 6. Fig. 5 shows that the stiffness $(S)$ of lignin modified asphalt mortar increased with increasing lignin fiber content and decreased with rising temperature, indicating that the addition of lignin fiber enhanced the cracking potential of the lignin modified asphalt mortars, so had a negative effect on the cracking resistance of asphalt mortars; increasing temperature would improve the cracking resistance of lignin modified asphalt mortar. Fig. 6 shows that the creep rate $(m)$ of the lignin modified asphalt mortars slightly decreased with increasing lignin fiber content, and significantly increased with a rise of temperature. It is well known that the higher the creep rate $(m)$, the quicker the stress could be released, and hence the better the cracking resistance of the asphalt mortars. So, increasing temperature would improve the cracking resistance of lignin modified asphalt mortar, and this was consistent with the lowtemperature creep stiffness analysis. 


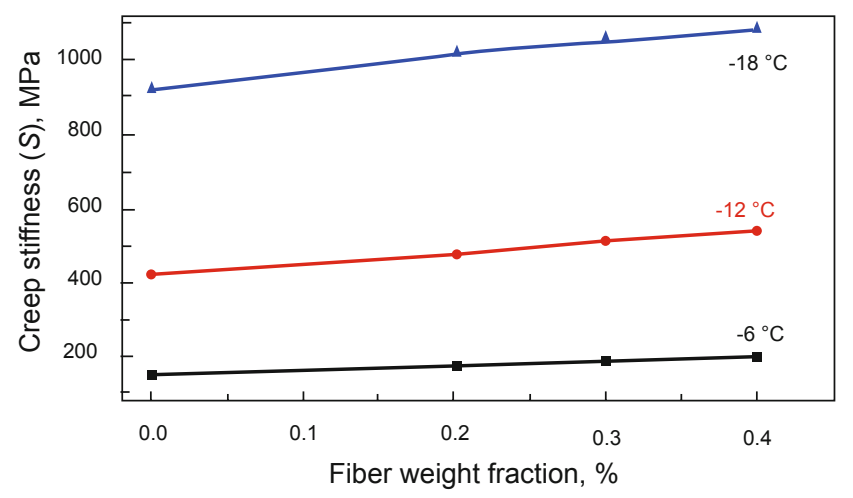

Fig. 5 Creep stiffness $(S)$ of lignin modified asphalt mortar

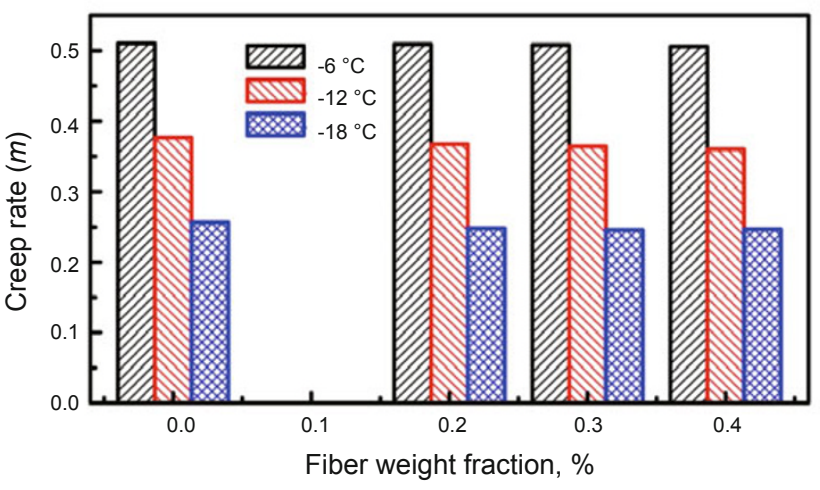

Fig. 6 Creep rate $(m)$ of lignin modified asphalt mortar

\section{Conclusions}

Laboratory experiments were designed to study physical properties and reinforcement effects of fibers and DOA in asphalt mortar. The following conclusions were reached:

Fiber and DOA can significantly improve asphalt mortar's softening point, penetration, viscosity and cone penetration. Fibers can reinforce asphalt mortar through their functions of spatial networking, absorption and adhesion of asphalt, and the reinforcement effects were also dependent on fiber's structures and properties including their shape, size and tensile strengths. The criteria used to select an optimal fiber and DOA concentration include viscosity, softening point, and cone penetration. Test results indicated that a mineral or lignin fiber concentration of $0.3 \%$ was desirable, while the desirable content of DOA or carbon fiber was $4 \%$. Our future efforts are to perform mechanical testing including on fatigue, static and repeated creep, and wheel tracking to characterize the asphalt mixtures made by fiber modified asphalt mortars discussed in this paper.

\section{Acknowledgements}

The work is supported by the National Natural Science Foundation of China (51008307), the Fundamental Research Funds for the Central Universities (09CX04039A), and the Graduate Student Innovation Project of China University of Petroleum (East China) (12CX06055A).

\section{References}

Airey G, Collop A, Zoorob S, et al. The influence of aggregate, filler and bitumen on asphalt mixture moisture damage. Constr Build Mater. 2008. 22(9): 2015-24

Bruce R W. The Pavement Performance and Life-cycle Cost Impacts of Carbon Fiber Modified Hot Mix Asphalt. M.S. Thesis. Michigan Technological University. 2003

Chen J S and Lin K Y. Mechanism and behavior of bitumen strength reinforcement using fibers. J Mater Sci. 2005. 40: 87-95

Chen $\mathrm{H}, \mathrm{Li} \mathrm{N}, \mathrm{Hu} \mathrm{C}$, et al. Mechanical performance of fibers-reinforced asphalt mixture. J Chan Univ (Nat Sci Ed). 2004. 24 (2): 1-5

Castro M and Sanchez A. Estimation of asphalt concrete fatigue curves-a damage theory approach. Constr Build Mater. 2008. 22(6): 1232-8

Chen $\mathrm{X}$ and Huang B. Evaluation of moisture damage in hot mix asphalt using simple performance and superpave indirect tensile tests. Constr Build Mater. 2008. 22(9): 1950-62

Echols J. New mix method for fiber-reinforced asphalt. Public Works. 1989. 119 (8): $72-3$

Fitzgerald R L. Novel applications of carbon fiber for hot mix asphalt reinforcement and carbon-carbon pre-forms. M.Sc. Thesis. Michigan Technological University. 2000

Fu S, Lauke B, Mader E, et al. Tensile properties of short-glass-fiberand short-carbon-fiber-reinforced polypropylene composites. Compos: Part A. 2000. 31: 1117-25

Gorkem C and Sengoz B. Predicting stripping and moisture induced damage of asphalt concrete prepared with polymer modified bitumen and hydrated lime. Constr Build Mater. 2009. 23(6): 2227-36

Hassan H, Al-Oraimi S and Taha R. Evaluation of open-graded friction course mixtures containing cellulose fibers and styrene butadiene rubber polymer. J Mater Civ Eng. 2005. 17(4): 415-22

Huang H and White T D. Dynamic properties of fiber-modified overlay mixture. Trans Res Rec. 1996. 1545: 98-104

Li V C. Postcrack scaling relations for fiber reinforced cementitious composites. J Mater Civil Eng. 1992. 4(1): 41-57

Maurer D A and Malasheskie G J. Field performance of fabrics and fibers to retard reflective cracking. Geotext Geomem. 1989. 8: 23967

Peltonen P. Wear and deformation of characteristics of fiber reinforced asphalt pavements. Constr Build Mater. 1991. 5: 18-22

Putman B J and Amirkhanian S N. Utilization of waste fibers in stone matrix asphalt mixtures. Resources, Conserv Recycle. 2004. 42: 26574

Rahnama E. A comparison on the performance of styrene-butadienestyrene (SBS) polymer and textile fibers modifying asphalt concrete (AC). M.Sc. Thesis. Iran University of Science and Technology. Iran. 2009

Ramsamooj D V. An innovative technique for using polymer composites in airport pavement rehabilitation. Composites: Part B. 2001. 32(1): $57-66$

Tapkin S. The effect of polypropylene fibers on asphalt performance. Build Environ. 2008. 43: 1065-71

Tapkin S, Çevik A and Uşar Ü. Prediction of Marshall test results for polypropylene modified dense bituminous mixtures using neural networks. Expert Systems with Applications. 2010. 37: 4660-4670

$\mathrm{Wu}$ S, Ye Q and Li N. Investigation of rheological and fatigue properties of asphalt mixtures containing polyester fibers. Constr Build Mater. 2008. 22(10): 2111-5

Xu Q W, Chen H X and Prozzi J A. Performance of fiber reinforced asphalt concrete under environmental temperature and water effects. Constr Build Mater. 2010. 24(10): 2003-2010

Yildirim Y. Polymer modified asphalt binders. Constr Build Mater. 2007. 21: $66-72$

Zhang W F, Huang Z H, Guo Z, et al. Porous carbons prepared from deoiled asphalt and their electrochemical properties for supercapacitors. Mater Lett. 2010. 64: 1868-1870

(Edited by Zhu Xiuqin) 